Article

\title{
Efficacy of Low-Molecular-Weight Fucoidan as a Supplemental Therapy in Metastatic Colorectal Cancer Patients: A Double-Blind Randomized Controlled Trial ${ }^{+}$
}

\author{
Hsiang-Lin Tsai ${ }^{1,2}, \ddagger$, Chi-Jung Tai ${ }^{3,4, \ddagger}$, Ching-Wen Huang ${ }^{1,2}$, Fang-Rong Chang ${ }^{3}$ and \\ Jaw-Yuan Wang 1,2,5,6,7,8,*
}

1 Division of Colorectal Surgery, Department of Surgery, Kaohsiung Medical University Hospital, Kaohsiung Medical University, Kaohsiung 807, Taiwan; chunpin870132@yahoo.com.tw (H.-L.T.); baseball5824@yahoo.com.tw (C.-W.H.)

2 Department of Surgery, Faculty of Medicine, College of Medicine, Kaohsiung Medical University, Kaohsiung 807, Taiwan

3 Graduate Institute of Natural Product, College of Pharmacy, Kaohsiung Medical University, Kaohsiung 807, Taiwan; taichijung@gmail.com (C.-J.T.); aaronfrc@kmu.edu.tw (F.-R.C.)

4 Department of Family Medicine, Pingtung Hospital, Ministry of Health and Welfare, Pingtung 928, Taiwan

5 Graduate Institute of Clinical Medicine, College of Medicine, Kaohsiung Medical University, Kaohsiung 807, Taiwan

6 Center for Biomarkers and Biotech Drugs, College of Medicine, Kaohsiung Medical University, Kaohsiung 807, Taiwan

7 Research Center for Environmental Medicine, College of Medicine, Kaohsiung Medical University, Kaohsiung 807, Taiwan

8 Research Center for Natural Products \& Drug Development, Kaohsiung Medical University, Kaohsiung 807, Taiwan

* Correspondence: jawyuanwang@gmail.com; Tel.: +886-7-3122-805; Fax: +886-7-3114-679

+ Presented at the Gastrointestinal Cancer Symposium of the American Society of Clinical Oncology, San Francisco, CA, USA, 19-21 January 2017.

$\ddagger$ The authors have contributed equally to this work.

Academic Editor: Vassilios Roussis

Received: 24 March 2017; Accepted: 18 April 2017; Published: 21 April 2017

\begin{abstract}
Background: Low-molecular-weight fucoidan (LMF) is widely used as a food supplement for cancer patients. However, all of the studies are in vitro or were conducted using mice. Therefore, powerful clinical evidence for LMF use is relatively weak. This study aimed to evaluate the efficacy of LMF as a supplemental therapy to chemo-target agents in metastatic colorectal cancer (mCRC) patients. Methods: We conducted a prospective, randomized, double-blind, controlled trial to evaluate the efficacy of LMF as a supplemental therapy to chemotarget agents in patients with metastatic colorectal cancer (mCRC). Sixty eligible patients with mCRC were included. Finally, 54 patients were enrolled, of whom 28 were included in the study group and 26 in the control group. The primary endpoint was the disease control rate (DCR), and secondary endpoints included the overall response rate (ORR), progression-free survival (PFS), overall survival (OS), adverse effects (AEs), and quality of life (QOL). Results: The DCRs were $92.8 \%$ and $69.2 \%$ in the study and control groups, respectively $(p=0.026)$, in a median follow-up period of 11.5 months. The OS, PFS, ORR, AEs, and QOL did not significantly differ between the two groups. Conclusion: This is the first clinical trial evaluating the efficacy of LMF as a supplemental therapy in the management of patients with mCRC. The results indicate that LMF combined with chemotarget agents significantly improved the DCR.
\end{abstract}


Keywords: low-molecular-weight fucoidan; metastatic colorectal cancer; supplemental therapy; disease control rate

\section{Introduction}

Fucoidan is an aggregate name for algal fucose-enriched sulfated polysaccharides extracted from the extracellular matrix of brown, green, and red seaweeds [1]. Fucoidan was first introduced by Dr. Kylin in 1913 while analyzing the reason behind the lower incidence of cancer in Okinawa, Japan [2]. Since then, more than 1400 studies focusing on its biological activities have been conducted. In particular, the antioxidant, anticancer, anti-inflammatory, and anti-proliferative activities of fucoidan have attracted considerable attention [3]. Therefore, fucoidan has become a widely used food supplement in Asia, especially in Japan, China, Taiwan, and Australia. The annual production value of fucoidan-related products is more than US $\$ 100$ million.

Many basic extraction methods of fucoidan products are available, including hot water, acid, ethanol, and alkaline extraction [4]. However, the production rate of fucoidan is low. Therefore, enzyme- [5], microwave- [6], and ultrasound-assisted extraction methods [7] and pressurized liquid extraction were developed [8]. According to different extraction methods, the molecular weight of fucoidan products can range from 20,000 to 200,000 daltons or from 400 to 5000 daltons, which is called low-molecular-weight fucoidan (LMF) [9]. The structure of fucoidan principally consists of an $\alpha$-1,3-linked or $\alpha$-1,4-linked backbone, mainly with repeated L-fucose and sulfate units, along with small quantities of D-galactose, D-xylose, D-mannose, and uronic acid [10]. The structure and amount of sulfate groups affect the anticancer effect of fucoidan [11].

Fucoidan and LMF are widely used as a complementary therapy or a food supplement in complementary alternative medicine. Since 2002, more than 200 patients with cancer have been receiving fucoidan as a complementary therapy in the clinic of Dr. Tachikawa Daisuke from Japan [12]. According to case reports in his book, fucoidan had beneficial effects on patients with colorectal, pancreatic, bladder, uterine, lung, liver, breast, and prostate cancers. Most of these patients consumed fucoidan while receiving surgery, chemotherapy, or radiotherapy. These patients received a daily dosage of $1-5 \mathrm{~g}$ of fucoidan. Fucoidan reduced the tumor size and the adverse effects (AEs) of chemotherapy and improved the quality of life (QOL). A recent study reported that LMF enhanced the responses of radiotherapy and chemotherapy. In addition, fucoidan reduced AEs and improved QOL. However, these studies were not conducted under strict clinical evaluation and protocols [13].

Two clinical trials have evaluated the efficacy of fucoidan in cancer patients. A randomized trial was performed on 20 advanced or recurrent colorectal cancer patients [14]. Patients were scheduled to undergo FOLFOX6 or FOLFIRI chemotherapy. A high-molecular-weight product of fucoidan, which was derived from Cladosiphon okamuranus, was used in the fucoidan group. In the study group, each patient received $150 \mathrm{~mL} /$ day of liquid that contained $4.05 \mathrm{~g}$ fucoidan for six months from the initial day of chemotherapy. The result showed that fucoidan regulated the occurrence of fatigue during chemotherapy. The second clinical trial demonstrated an open label noncrossover study in breast cancer patients taking letrozole or tamoxifen [15]. Patients took oral fucoidan, derived from Undaria pinnatifida extract, for a three-week period (500 mg capsule twice daily). The results suggested that fucoidan in the studied form and dosage could be taken concomitantly with letrozole and tamoxifen, without the risk of clinically significant interactions.

LMF inhibits tumor angiogenesis through the downregulation of HIF-1/VEGF signaling under hypoxia [16], as well as breast cancer cell growth in vitro and in vivo through the involvement of ubiquitin proteasome pathway (UPP)-mediated transforming growth factor- $\beta$ (TGF $\beta$ ) receptor degradation [17]. In lung cancer, LMF induced inhibitory activities through the Smurf2-dependent UPP in TGF $\beta$ receptor degradation [18]. Likewise, LMF increases the microRNA-29b level to regulate the DNMT3B-MTSS1 axis and inhibits EMT (Epithelial Mesenchymal Transition) in human 
hepatocellular carcinoma cells [19]. A prospective, open-label, single-arm clinical study was conducted for 20 advanced cancer patients by using LMF ( $4 \mathrm{~g}$ daily in aqueous solution) via oral administration for at least four weeks [20]. The study recruited 20 patients with 10 different origin cancers, including lung, colon, liver, pancreas, stomach, sarcoma, uterus, breast, prostate, head, and neck cancers. The main proinflammatory cytokines, including interleukin-1 $\beta$ (IL-1 $\beta$ ), IL-6, and tumor necrosis factor- $\alpha$ (TNF- $\alpha)$ were significantly reduced after two weeks of fucoidan ingestion.

In Taiwan, colorectal cancer (CRC) has become the most common malignancy in the most recent eight years [21]. In addition, CRC is the third most common cancer in the United States. Personalized treatment protocols have shown beneficial effects in patients. However, the survival rate and QOL of patients with metastatic CRC (mCRC) still require improvement. The development of an efficient auxiliary therapy can be helpful. The previous clinical trial, which applied high-molecular-weight fucoidan in colorectal cancer patients, is a relatively small sample size trial without blindness. Additionally, target therapy should be administrated according to the National Comprehensive Cancer Network (NCCN) guideline. Due to the reason mentioned above, the result of the study couldn't give us strong evidence for current clinical practice. Therefore, we performed the first prospective, randomized, double-blind, controlled trial to investigate the efficacy of LMF as a supplemental therapy to chemotarget agents in patients with mCRC.

\section{Materials and Methods}

\subsection{Study Design}

This prospective, randomized, double-blind, controlled trial was conducted between December 2014 and August 2016. Initially, we enrolled 60 patients with mCRC and divided them into two groups: study group $(n=30)$ and control group $(n=30)$. In these patients, folinic acid, 5-fluorouracil, and irinotecan (FOLFIRI), plus bevacizumab therapy $(5 \mathrm{mg} / \mathrm{Kg})$, was used biweekly as the first-line chemotarget regimen. In the study group, each patient received $4 \mathrm{~g}$ of fucoidan BID (bis in die, which in Latin means twice a day). In the control group, each patient orally received $4 \mathrm{~g}$ of cellulose powder BID. The prescribed period was six months. All clinical data were collected after obtaining informed consent from all patients, and the study protocol was approved by the institutional review board-II of Kaohsiung Medical University Hospital (Identification code: KMUHIRB-2014-09-01[II], approval date: 21 October 2014).

\subsection{Materials}

The low-molecular-weight fucoidan (LMF) powders in this trial were derived from Sargassum hemiphyllum and prepared by (Hi-Q Marine Biotech International Ltd. (Taipei, Taiwan), which has a Good Manufacturing Practice certification, and its LMF powder has been qualified as a Symbol of National Quality product in Taiwan. LMF was obtained by enzyme hydrolysis of the original fucoidan. The characteristics of LMF were an average molecular weight of $0.8 \mathrm{KDa}(92.1 \%)$, fucose content of $210.9 \pm 3.3 \mathrm{mmol} / \mathrm{g}$, and sulfate content of $38.9 \% \pm 0.4 \%(w / w)$ [22]. The extraction method followed the method mentioned before, with technological modifications [23]. LMF and cellulose powders were packaged in an aluminum foil bag with the same appearance and weight. Each packet had $4 \mathrm{~g}$ of powder in it.

\subsection{Patient Selection}

The inclusion criteria for the study were as follows: (1) age between 20 and 80 years; (2) presence of either metachronous or synchronous mCRC; (3) female patients who were prepared to not breastfeed; (4) no presence of major underlying diseases, such as cardiovascular, cerebrovascular, malignant hypertension, inadequate hematological function, kidney, liver, and other major diseases, or other malignancies; (5) confirmation of mCRC by reports from pathologists or radiologists; and (6) willingness to sign an informed consent form. Patients who did not meet the inclusion criteria 
or were unwilling to participate were excluded. In addition, patients who could not tolerate regular chemotarget agents or were lost to follow-up within six months were excluded. The demographic and clinical characteristics of the patients were recorded.

\subsection{Randomization and Blinding}

Patients were randomly assigned with an equal probability. A randomization table was created using Microsoft Excel. After inclusion, each patient was assigned a project number, which represented a specific treatment plan. The randomization list was only available to the sample manufacturer; it was unblinded after the completion of the research.

\subsection{Study Protocols}

Patients were randomly assigned to study and control groups. Both groups received chemotherapy with targeted therapy according to the National Comprehensive Cancer Network guideline (https:/ / www.nccn.org/). Patients in the study group received $4 \mathrm{~g}$ of LMF powder BID for six months. Patients in the control group received $4 \mathrm{~g}$ of cellulose powder BID for six months.

All patients underwent laboratory tests, abdominal computed tomography (CT) or other imaging studies, and colonoscopy before the trial. They underwent blood examination and AE evaluation, and filled in a QOL questionnaire every time they were admitted for regular chemotargeted therapy. Adverse events were graded according to the Common Terminology Criteria for Adverse Events (CTCAE), Version 4.02, and the European Organization for Research and Treatment of Cancer (EORTC) QLQ-CR29. The QOL questionnaire was modified from the EORTC QLQ-C30.

\subsection{Efficacy Objectives}

\subsubsection{Primary Objective}

We selected the disease control rate (DCR) as the primary objective because we focused on the auxiliary effects, and not on the therapeutic effects, of LMF.

\subsubsection{Secondary Objectives}

We included six secondary endpoints: (1) objective response rate (ORR); (2) overall survival rate (OS); (3) progression-free survival (PFS) rate; (4) incidence; (5) severity of AEs; and (6) QOL.

\subsubsection{Safety Objective}

If patients experienced adverse events and a laboratory toxicity of more than grade 2 according to the National Cancer Institute CTCAE, the treatment was withheld.

\subsection{Length of Study}

The recruitment period of this study was expected to be 24 months (a median follow-up period of 11.5 months). The trial was continued for six months to reach its primary objective. Survival data were collected until death or a patient's request for withdrawal.

\subsection{Efficacy Outcome Measures}

The response was assessed radiologically through CT, magnetic resonance imaging, bone scanning, or positron emission tomography, and the most satisfactory response was recorded. The first response was assessed after the sixth cycle in patients who received targeted therapy combined with FOLFIRI chemotherapy. Investigators classified responses according to the Response Evaluation Criteria in Solid Tumors (Version 1.1) [24].

A complete response $(\mathrm{CR})$ is defined as the disappearance of all target lesions. A partial response (PR) is defined as a decrease of at least $30 \%$ in the sum of the longest diameter, taking the sum of 
the longest diameter at the baseline as a reference point. Progressive disease (PD) is defined as an increase of at least $20 \%$ in the sum of the longest diameter of target lesions, taking the smallest sum of the longest diameters recorded before the patient started receiving treatment as a reference point. PD can also be defined as the identification of one or more new lesions. Stable disease (SD) is defined as having neither a sufficient shrinkage to qualify for a PR nor a sufficient increase to qualify for a PD. OS is defined as the date of death or the last recorded date of follow-up. Moreover, we reported the best response, which is defined as the best response recorded by the investigators. AEs and AESIs (Adverse Event of Special Interests) were assessed according to the NCI CTCAE, Version 4.03 [25].

\subsection{Statistical Analysis}

All data were analyzed using the Statistical Package for Social Sciences, version 19.0 (SPSS, Inc., Chicago, IL, USA). Data are presented as the mean \pm standard deviation. The chi-square test, Wilcoxon rank sum test, and Fisher's exact test were used to analyze the potential correlation among the expression of biological markers, adverse events, and QOL of patients. OS was defined as the time from the date of primary treatment to the date of death from any cause or until the date of the last follow-up. PFS was defined as the time from the date of primary treatment to the date of diagnosis of PD or to the date of the last follow-up. The cumulative OS and PFS rates were calculated using the Kaplan-Meier method, and differences in the survival rates between the study and control groups were analyzed using the log-rank test. To minimize the interpretation bias, OS analysis was applied. A $p$ value of $<0.05$ was considered statistically significant.

\section{Results}

\subsection{Baseline Characteristics of Patients}

From December 2014 to August 2016, sixty patients with a diagnosis of mCRC were included (Figure 1). Of these patients, six could not complete the six-month trial, two had severe AEs, two were lost to follow-up, one died of pneumonia, and one died of severe upper gastrointestinal bleeding. Finally, 54 patients were enrolled, of whom 28 were included in the study group and 26 were part of the control group.

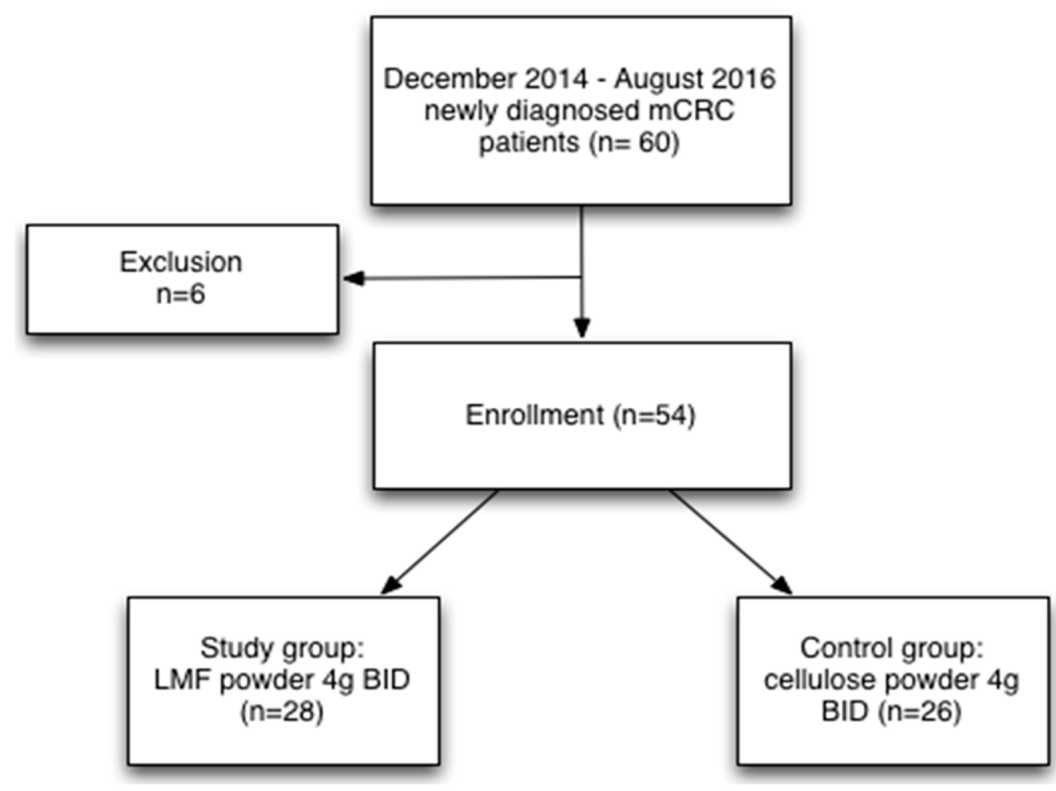

Figure 1. Flowchart illustrating the selection process. Presentation of the cohort and the selection of patients with metastatic colorectal cancer. 
Demographic characteristics, such as sex, age, metachronous $\mathrm{mCRC}$, synchronous $\mathrm{mCRC}$, median follow-up period, metastasectomy, and pretreatment laboratory examinations (white blood cell and platelet counts; hemoglobin, glutamic-pyruvic transaminase, creatinine, and carcinoembryonic antigen levels; and body weight), were similar between the study and control groups (Table 1).

Table 1. Clinicopathological features of 54 enrolled patients with stage IV colorectal cancer, comprising 28 patients in the study group and 26 in the control group, evaluated using the chi-square test and Wilcoxon rank sum test.

\begin{tabular}{|c|c|c|c|c|}
\hline & Total & Study Group & Control Group & \\
\hline & $(n=54)$ & $(n=28)$ & $(n=26)$ & $p$-value \\
\hline & $\mathrm{N}$ & $\mathrm{N}(\%)$ & $\mathrm{N}(\%)$ & \\
\hline Gender & & & & $0.967^{\#}$ \\
\hline Male & 31 & $16(57.1)$ & $15(57.7)$ & \\
\hline Female & 23 & $12(42.9)$ & $11(42.3)$ & \\
\hline Age $(y / o) *$ & & & & $0.178^{\#}$ \\
\hline$<65$ & 36 & $21(75.0)$ & $15(57.7)$ & \\
\hline$\geq 65$ & 18 & $7(25.0)$ & $11(42.3)$ & \\
\hline $\operatorname{Age}(y / o) *$ & & & & 0.137 \#\# \\
\hline $\begin{array}{l}\text { Median } \pm \text { S.D * } \\
\text { (range) }\end{array}$ & & $\begin{array}{l}57.46 \pm 12.15 \\
\quad(30 \sim 79)\end{array}$ & $\begin{array}{c}62.38 \pm 11.72 \\
\quad(43 \sim 83)\end{array}$ & \\
\hline Stage IV & & & & $0.872^{\#}$ \\
\hline Synchronous & 40 & $21(75.0)$ & $19(73.1)$ & \\
\hline Metachronous & 14 & $7(25.0)$ & $7(26.9)$ & \\
\hline Metastasectomy & & & & $0.244^{\#}$ \\
\hline Yes & 12 & $8(28.6)$ & $4(15.4)$ & \\
\hline No & 42 & $20(71.4)$ & $22(84.6)$ & \\
\hline Follow-up (months) & & & & 0.117 \#\# \\
\hline $\begin{array}{l}\text { Median } \pm \text { S.D } \\
\text { (range) }\end{array}$ & & $\begin{array}{l}12.39 \pm 4.41 \\
(4 \sim 20)\end{array}$ & $\begin{array}{c}10.54 \pm 3.22 \\
\quad(4 \sim 16)\end{array}$ & \\
\hline Pre-WBC ${ }^{* *}(/ \mu \mathrm{L})$ & & & & $0.671 \#$ \\
\hline Mean \pm S.D * & & $7118 \pm 2669$ & $7330 \pm 2960$ & \\
\hline Median & & 7065 & 7045 & \\
\hline Pre-Hgb ${ }^{* *}(g / d L)$ & & & & 0.472 \#\# \\
\hline Mean \pm S.D * & & $11.89 \pm 1.78$ & $11.51 \pm 1.90$ & \\
\hline Median & & 11.80 & 11.45 & \\
\hline Pre-Platelet $(/ \mu \mathrm{L})$ & & & & 0.952 \#\# \\
\hline Mean \pm S.D * & & $303,964 \pm 99,869$ & $300,346 \pm 87,945$ & \\
\hline Median & & 278,500 & 292,500 & \\
\hline Pre-GPT ${ }^{* *}(\mathrm{U} / \mathrm{L})$ & & & & $0.646^{\# \#}$ \\
\hline Mean \pm S.D* & & $23.54 \pm 12.56$ & $20.92 \pm 6.80$ & \\
\hline Median & & 21.50 & 20.50 & \\
\hline Pre-Cr ${ }^{* *}(\mathrm{mg} / \mathrm{dL})$ & & & & 0.591 \#\# \\
\hline Mean \pm S.D * & & $0.96 \pm 0.75$ & $0.89 \pm 0.26$ & \\
\hline Median & & 0.815 & 0.835 & \\
\hline Pre-CEA ** $(n g / m L)$ & & & & $0.236^{\# \#}$ \\
\hline Mean \pm S.D* & & $989.9 \pm 3622.5$ & $35.05 \pm 60.78$ & \\
\hline Median & & 31.38 & 13.92 & \\
\hline Pre-Body weight $(\mathrm{kg})$ & & & & $0.382 \#$ \\
\hline Mean \pm S.D* & & $62.39 \pm 11.30$ & $59.50 \pm 11.90$ & \\
\hline Median & & 61.45 & 58.00 & \\
\hline
\end{tabular}

\# chi-square test; \#\# Wilcoxon rank sum test; ${ }^{\text {y }}$ /o: years old; S.D.: standard deviation; ${ }^{* *}$ WBC: white blood count; Hgb: hemoglobin; GPT: glutamic-pyruvic transaminase; Cr: creatinine; CEA: carcinoembryonic antigen.

\subsection{Primary Outcome}

The DCR, defined as the sum of the CR, PR, and SD rates, was significantly higher (by $23.6 \%$ ) in the study group than in the control group $(92.8 \%$ vs. $69.2 \% ; p=0.026$; Table 2$)$. 
Table 2. Comparison of disease control rates and objective response rates between the study and control groups using the chi-square test.

\begin{tabular}{ccccc}
\hline & Total & Study Group & Control Group & \\
\hline & $(n=54)$ & $(n=28)$ & $(n=26)$ & $p$-value \\
Disease control rate & & & & 0.026 \\
Yes (CR+PR+SD) & 44 & $26(92.8)$ & $18(69.2)$ & \\
No (PD) & 10 & $2(7.2)$ & $8(30.8)$ & 0.284 \\
$\begin{array}{c}\text { Objective response rate } \\
\text { Yes (CR+PR) * }\end{array}$ & 29 & $17(60.7)$ & $12(46.2)$ & \\
No (SD+PD) * & 25 & $11(39.3)$ & $14(53.8)$ &
\end{tabular}

* CR: complete response; PR: partial response; SD: stable disease; PD: progressive disease classified using RECIST criteria, Version 1.1.

\subsection{Secondary Outcomes}

The ORR (sum of the CR and PR rates) was comparable in the study group and the control group (60.7\% vs. $46.2 \% ; p=0.284$; Table 2). Compared with the control group, the study group exhibited a trend of improved OS (18.04 \pm 0.91 vs. $12.96 \pm 0.83$ months; $p=0.092)$ and PFS (15.93 \pm 1.20 vs. $10.80 \pm 1.06$ months; $p=0.075$ ); however, the difference was not significant (Figures 2 and 3 ).

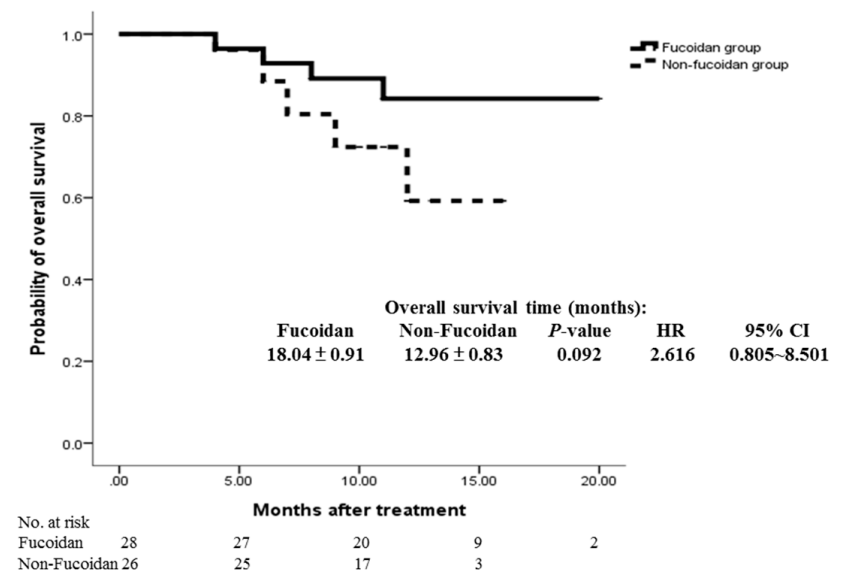

Figure 2. Cumulative overall survival rates of the study and control groups were analyzed using the Kaplan-Meier method, with differences compared using the log-rank test. No significant differences were observed between the two groups $(p=0.092)$.

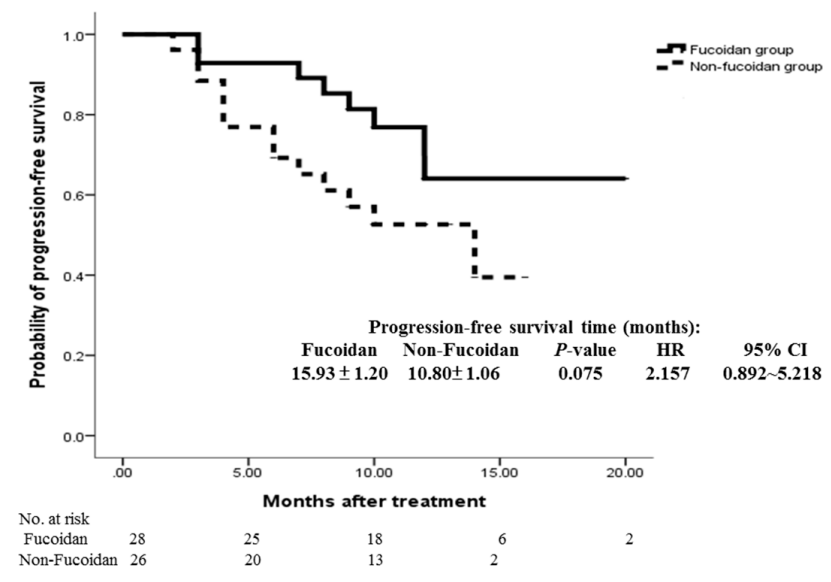

Figure 3. Cumulative progression-free survival rates of the study and control groups were analyzed using the Kaplan-Meier method with differences compared using the log-rank test. No significant differences were observed between the two groups $(p=0.075)$. 


\subsection{Evaluation of Adverse Effects}

No severe AEs were observed in both groups during the trial period. Furthermore, the discontinuation of treatment because of drug-related AEs was not reported. No death was observed to be related to fucoidan treatment. The duration and treatment intensity of the chemotargeted therapy were similar in both groups.

The deflection of all baseline blood examinations levels was similar in both groups (Table 3). The grading of leukopenia, anemia, and thrombocytopenia also exhibited a similar distribution (Table 4). Moreover, the control group exhibited a trend of a higher incidence of oral mucositis $(65.4 \%$ vs. $50 \% ; p=0.253)$, pruritus ( $53.9 \%$ vs. $35.7 \% ; p=0.180)$, vomiting $(53.9 \%$ vs. $35.7 \% ; p=0.180)$, taste problem ( $80.8 \%$ vs. $64.3 \% ; p=0.177)$, and bloody stool $(30.8 \%$ vs. $14.3 \% ; p=0.145)$ than the study group; however, the difference was not significant (Table 4 ).

Table 3. Deflection of biochemical indices.

\begin{tabular}{|c|c|c|c|c|c|c|c|}
\hline & \multicolumn{3}{|c|}{ Study Group $(n=28)$} & \multicolumn{3}{|c|}{ Control Group $(n=26)$} & $p$-value * \\
\hline WBC change $(/ \mu \mathrm{L})$ & -4508 & 2444 & -4435 & -4647.69 & 2821 & -4390 & 0.8558 \\
\hline Platelet change $(/ \mu \mathrm{L})$ & $-144,750$ & 120,530 & $-92,000$ & $-132,808$ & 86,573 & $-124,000$ & 0.8152 \\
\hline GPT change (U/L) & 75.25 & 122.61 & 40.50 & 58.73 & 90.57 & 29.00 & 0.5974 \\
\hline Creatinine change $(\mathrm{mg} / \mathrm{dL})$ & 0.52 & 0.86 & 0.16 & 0.69 & 1.52 & 0.16 & 0.2354 \\
\hline
\end{tabular}

* Wilcoxon rank sum test; White blood cell (WBC) count change = Minimum WBC count - baseline WBC count; Hemoglobin $(\mathrm{Hgb})$ level change $=$ Minimum Hgb level - baseline Hgb level; Platelet count change = Minimum platelet count - baseline platelet count; glutamic-pyruvic transaminase (GPT) level change = Maximum GPT level baseline GPT level; creatinine level change = Maximum creatinine level - baseline creatinine level; carcinoembryonic antigen (CEA) level change $=$ last CEA level - baseline CEA level; body weight change $=$ minimum body weight baseline body weight.

Table 4. Comparison of the incidence of adverse effects and severe adverse effects between the study and control groups evaluated using the chi-square test.

\begin{tabular}{ccccccc}
\hline & $\begin{array}{c}\text { Study } \\
\text { Group } \\
(\boldsymbol{n}=\mathbf{2 8}) \mathbf{( \% )}\end{array}$ & $\begin{array}{c}\text { Control } \\
\text { Group } \\
(\boldsymbol{n}=\mathbf{2 6}) \mathbf{( \% )}\end{array}$ & & $\begin{array}{c}\text { Study } \\
\text { Group } \\
(\boldsymbol{n}=\mathbf{2 8}) \mathbf{( \% )}\end{array}$ & $\begin{array}{c}\text { Control } \\
\text { Group } \\
(\boldsymbol{n}=\mathbf{2 6}) \mathbf{( \% )}\end{array}$ & \\
\hline Grade & I-IV & I-IV & $p$-value & III \& IV & III \& IV & $p$-value \\
Leukopenia & $18(64.3 \%)$ & $17(65.4 \%)$ & 0.9327 & $7(25 \%)$ & $7(26.9 \%)$ & 0.8719 \\
Anemia & $22(78.6 \%)$ & $17(65.4 \%)$ & 0.2797 & $8(28.6 \%)$ & $8(30.8 \%)$ & 0.8597 \\
Thrombocytopenia & $7(25 \%)$ & $4(15.4 \%)$ & 0.3807 & $1(3.6 \%)$ & $2(7.7 \%)$ & 0.5089 \\
Abnormal liver function & $14(50 \%)$ & $15(57.7 \%)$ & 0.5710 & $5(17.9 \%)$ & $4(15.4 \%)$ & 0.8075 \\
Impaired renal function & $12(42.9 \%)$ & $6(23.1 \%)$ & 0.1234 & $1(3.6 \%)$ & $4(15.4 \%)$ & 0.1346 \\
Mucositis oral & $14(50 \%)$ & $17(65.4 \%)$ & 0.2533 & $1(3.6 \%)$ & $1(3.8 \%)$ & 0.9574 \\
Pruritus & $10(35.7 \%)$ & $14(53.9 \%)$ & 0.1803 & 0 & 0 & \\
Vomiting & $10(35.7 \%)$ & $14(53.9 \%)$ & 0.1803 & 0 & $3(11.5 \%)$ & 0.0644 \\
Taste problem & $18(64.3 \%)$ & $21(80.8 \%)$ & 0.1766 & $2(7.1 \%)$ & $2(7.7 \%)$ & 0.9386 \\
Bloody stool & $4(14.29 \%)$ & $8(30.77 \%)$ & 0.1454 & 0 & $1(3.85 \%)$ & 0.2948 \\
Alopecia & $26(92.9 \%)$ & $25(96.1 \%)$ & 0.5971 & $10(35.7 \%)$ & $9(34.6 \%)$ & 0.9326 \\
\hline
\end{tabular}

Severe adverse effects: grade 3 and 4 adverse effects. Grading modified from the Common Terminology Criteria for Adverse Events, Version 4.02, and the European Organization for Research and Treatment of Cancer QLQ-CR29.

\subsection{Quality of Life}

Both groups were similar in terms of the limitation of daily activities, limitation of walking, anxiety, fatigue, weakness, and issues of personal hygiene. Grade 3 events including the limitation of pursuing hobbies, trouble sleeping, and depression were not significantly different between the control group and the study group (Table 5). 
Table 5. Quality of life grading between the study and control groups during treatment by using Fisher's exact test.

\begin{tabular}{|c|c|c|c|c|c|c|c|c|c|}
\hline \multirow[b]{2}{*}{ Grading } & \multicolumn{4}{|c|}{ Study Group $(n=28)$} & \multicolumn{4}{|c|}{ Control Group $(n=26)$} & \multirow[b]{2}{*}{$p$-value } \\
\hline & 0 & 1 & 2 & 3 & 0 & 1 & 2 & 3 & \\
\hline Limited in doing daily activities & 0 & 12 & 13 & 3 & 0 & 10 & 10 & 6 & 0.5142 \\
\hline Limited in doing hobbies & 4 & 15 & 6 & 3 & 0 & 11 & 13 & 2 & 0.0553 \\
\hline Limited in walking & 9 & 14 & 3 & 2 & 6 & 9 & 9 & 2 & 0.2197 \\
\hline Trouble sleeping & 7 & 12 & 6 & 3 & 4 & 5 & 14 & 3 & 0.0784 \\
\hline Depression & 7 & 15 & 6 & 0 & 1 & 16 & 8 & 1 & 0.0971 \\
\hline Anxiety & 6 & 12 & 9 & 1 & 3 & 12 & 11 & 0 & 0.5826 \\
\hline Fatigue & 3 & 12 & 11 & 2 & 0 & 11 & 12 & 3 & 0.4520 \\
\hline Feel weakness & 1 & 15 & 9 & 3 & 0 & 9 & 14 & 3 & 0.3108 \\
\hline Need help with personal hygiene & 18 & 5 & 4 & 1 & 12 & 10 & 2 & 2 & 0.3031 \\
\hline
\end{tabular}

\section{Discussion}

Approximately 1.2 million patients develop CRC and 600,000 patients die of CRC worldwide annually [26]. In recent years, new anticancer drugs that target oncogenic signaling pathways have been developed; these drugs have demonstrated a prominent efficacy level in the treatment of mCRC [27]. Currently, several EGFR monoclonal antibodies are used for treating mCRC [28]. For example, Erbitux ${ }^{\circledR}$ (cetuximab) and Vectibix ${ }^{\circledR}$ (panitumumab) were approved as first-line treatment for mCRC in 2004 and 2006, respectively $[29,30]$. Among the major downstream pathways activated by EGFR, the RAS mutation played a crucial role in drug resistance [31,32]. RAS, KRAS, and NRAS mutations are detected in approximately $50 \%, 40 \%$, and $3-5 \%$ of patients with CRC, respectively [33,34]. The evaluation of RAS mutations has become critical in current clinical practice. Although a personalized treatment plan is effective, the five-year survival rate of patients with mCRC is still approximately $11 \%$ [26]. Therefore, developing other therapeutic alternative methods is important to improve the survival rates of patients with mCRC.

Fucoidan and LMF are widely used as a complementary therapy in patients with cancer; nevertheless, no clinical evidence of their efficacy is available. To the best of our knowledge, this is the first clinical trial evaluating the efficacy of fucoidan. In our study, the patients in the study group received $4 \mathrm{~g}$ of LMF BID powder for six months. The results reveal that the DCR was significantly higher, with an increase of $23.6 \%$ for the study group when compared to the control group. Moreover, the ORR tended to be insignificantly higher in the study group when compared to the control group. A trend of improved OS and PFS was also noted in our analysis. Additional studies with a larger sample size should be conducted to evaluate whether LMF eventually improves OS and PFS.

According to previous in vitro and animal studies, Fucoidan has a cytotoxic effect in the HCT-15 colon cancer cell line [35]. Fucoidan also inhibits the migration and proliferation of HT-29 human colon cancer cells via the phosphoinositide-3 kinase/Akt/mechanistic target of rapamycin pathways [36]. It was demonstrated that fucoidan represses cancer metastasis by inhibiting vascular endothelial growth factor (VEGF) and matrix metalloproteinases (MMPs) in Lewis tumor-bearing mice [37]. However, the effect of fucoidan in combination with a chemotarget agent has not been evaluated. Furthermore, no scientific report has discussed whether fucoidan can downregulate the EGFR/KRAS/BRAF pathway. It needs further researches to explain the possible anti-cancer mechanism in colon cancer patients.

Previous studies involved clinical observations without systemic evaluations. No study has investigated the hematological effect of fucoidan in vivo. In our study, the grading of leukopenia, anemia, and thrombocytopenia was similar in both groups. Fucoidan has been reported to protect against liver injury and liver fibrosis in mice [38,39]. However, we did not observe this benefit with regard to chemotarget agents. Likewise, LMF could protect renal tubular cells from injury and reduce 
blood urea nitrogen and creatinine levels in mice [40,41]. In our study, the increase in creatinine levels was similar in both groups; nevertheless, grade III and IV renal impairment levels increased by $11.8 \%$ in the control group when compared to the study group, but not significantly. Fucoidan can prevent intestinal mucositis induced by chemotherapy in mice [42]. Our study determined that the study group had a $16.5 \%$ lower incidence rate of taste problems than the control group. In an animal model, fucoidan attenuated existing allodynia and hyperalgesia [43].

\section{Conclusions}

This is the first randomized, double-blind, controlled trial evaluating the efficacy of LMF as a supplemental therapy in patients with $\mathrm{mCRC}$. Our study results demonstrate the advantages of LMF in improving the disease control rate (DCR). We believe that this study can provide insights into the development of cancer treatments, particularly in the combination of natural or herbal products with chemotarget agents.

Supplementary Materials: The following are available online at www.mdpi.com/1660-3397/15/4/122/s1, Table S1: The definitions of adverse effects grading, Table S2: The definitions of quality of life.

Acknowledgments: The low-molecular-weight fucoidan and cellulose powder used in this project were manufactured and provided for free by Hi-Q Marine Biotech International Ltd. (Taipei, Taiwan), and the funding was obtained by academia-industry cooperation (S102039). The authors acknowledge the Colorectal Cancer Group from the Cancer Center of Kaohsiung Medical University Hospital for their contribution in data collection. We acknowledge Wallace Academic Editing (www.editing.tw) for editing this manuscript. This study was also supported by grants from the Excellence for Cancer Research Center through funding by the Ministry of Science and Technology (MOST105-2325-B-037-001); the Ministry of Health and Welfare (MOHW106-TDU-B-212-144007); Health and Welfare Surcharge of Tobacco Products, Taiwan, Republic of China; Kaohsiung Medical University Hospital (KMUH103-3M28, KMUH98-8G06, KMHU100-0 M14, KMUHS10522, KMUHS10505, KMUHS10418, and KMUHGCRC2016002); Kaohsiung Medical University "Aim for the top University Grant" (KMU-TP105C01, KMU-TP105C11, KMU-TP106005, KMUTP105A14, KMU-DK106005, and SH000113 [Give2Asia]) and the Grant from Biosignature in Colorectal Cancers, Academia Sinica, Taiwan.

Author Contributions: All authors were involved in the concept and design of this study. Hsiang-Lin Tsai and Chi-Jung Tai were responsible for patient evaluation, document recording, manuscript writing, and statistical analysis. Jaw-Yuan Wang was responsible for coordinating with investigators. Ching-Wen Huang and Fang-Rong Chang were responsible for data collection and analysis. All authors contributed to reviewing the various drafts of the manuscript and approved the final version of the article.

Conflicts of Interest: The authors declare no conflict of interest.

\section{References}

1. Moussavou, G.; Kwak, D.H.; Obiang-Obonou, B.W.; Maranguy, C.A.; Dinzouna-Boutamba, S.D.; Lee, D.H.; Pissibanganga, O.G.; Ko, K.; Seo, J.I.; Choo, Y.K. Anticancer effects of different seaweeds on human colon and breast cancers. Mar. Drugs 2014, 12, 4898-4911. [CrossRef] [PubMed]

2. Zhang, Z.; Teruya, K.; Yoshida, T.; Eto, H.; Shirahata, S. Fucoidan extract enhances the anti-cancer activity of chemotherapeutic agents in MDA-MB-231 and MCF-7 breast cancer cells. Mar. Drugs 2013, 11, 81-98. [CrossRef] [PubMed]

3. Wang, J.; Zhang, Q.; Zhang, Z.; Li, Z. Antioxidant activity of sulfated polysaccharide fractions extracted from Laminaria japonica. Int. J. Biol. Macromol. 2008, 42, 127-132. [CrossRef] [PubMed]

4. Hahn, T.; Lang, S.; Ulber, R.; Muffler, K. Novel procedures for the extraction of fucoidan from brown algae. Process Biochem. 2012, 47, 1691-1698. [CrossRef]

5. Silchenko, A.S.; Kusaykin, M.I.; Kurilenko, V.V.; Zakharenko, A.M.; Isakov, V.V.; Zaporozhets, T.S.; Gazha, A.K.; Zvyagintseva, T.N. Hydrolysis of fucoidan by fucoidanase isolated from the marine bacterium, Formosa algae. Mar. Drugs 2013, 11, 2413-2430. [CrossRef] [PubMed]

6. Yuan, Y.; Macquarrie, D. Microwave assisted extraction of sulfated polysaccharides (fucoidan) from Ascophyllum nodosum and its antioxidant activity. Carbohydr. Polym. 2015, 129, 101-107. [CrossRef] [PubMed] 
7. Guo, X.; Ye, X.; Sun, Y.; Wu, D.; Wu, N.; Hu, Y.; Chen, S. Ultrasound effects on the degradation kinetics, structure, and antioxidant activity of sea cucumber fucoidan. J. Agric. Food Chem. 2014, 62, 1088-1095. [CrossRef] [PubMed]

8. Saravana, P.S.; Cho, Y.J.; Park, Y.B.; Woo, H.C.; Chun, B.S. Structural, antioxidant, and emulsifying activities of fucoidan from Saccharina japonica using pressurized liquid extraction. Carbohydr. Polym. 2016, 153, 518-525. [CrossRef] [PubMed]

9. Ye, J.; Li, Y.; Teruya, K.; Katakura, Y.; Ichikawa, A.; Eto, H.; Hosoi, M.; Hosoi, M.; Nishimoto, S.; Shirahata, S. Enzyme-digested Fucoidan Extracts Derived from Seaweed Mozuku of Cladosiphon novae-caledoniae kylin Inhibit Invasion and Angiogenesis of Tumor Cells. Cytotechnology 2005, 47, 117-126. [CrossRef] [PubMed]

10. Li, B.; Lu, F.; Wei, X.; Zhao, R. Fucoidan: Structure and bioactivity. Molecules 2008, 13, 1671-1695. [CrossRef] [PubMed]

11. Wu, L.; Sun, J.; Su, X.; Yu, Q.; Yu, Q.; Zhang, P. A review about the development of fucoidan in antitumor activity: Progress and challenges. Carbohydr. Polym. 2016, 154, 96-111. [CrossRef] [PubMed]

12. Tachikawa, D. Amzaing Power of Fucoidan (You Can Beat Cancer Too!!); Dacombook: Taipei, Taiwan, 2009.

13. Chen, W. Qi Ji Yi Sheng Chen Wei Hua 20 Nian Zhan Sheng 3 Ai; Fang Zhou Mu Ma Wen Hua: Xinbei, Taiwan, 2013.

14. Ikeguchi, M.; Yamamoto, M.; Arai, Y.; Maeta, Y.; Ashida, K.; Katano, K.; Miki, Y.; Kimura, T. Fucoidan reduces the toxicities of chemotherapy for patients with unresectable advanced or recurrent colorectal cancer. Oncol. Lett. 2011, 2, 319-322. [CrossRef] [PubMed]

15. Tocaciu, S.; Oliver, L.J.; Lowenthal, R.M.; Peterson, G.M.; Patel, R.; Shastri, M.; McGuinness, G.; Olesen, I.; Fitton, J.H. The Effect of Undaria pinnatifida Fucoidan on the Pharmacokinetics of Letrozole and Tamoxifen in Patients With Breast Cancer. Integr. Cancer Ther. 2016. [CrossRef]

16. Chen, M.C.; Hsu, W.L.; Hwang, P.A.; Chou, T.C. Low Molecular Weight Fucoidan Inhibits Tumor Angiogenesis through Downregulation of HIF-1/VEGF Signaling under Hypoxia. Mar. Drugs 2015, 13, 4436-4451. [CrossRef] [PubMed]

17. Hsu, H.Y.; Lin, T.Y.; Hwang, P.A.; Tseng, L.M.; Chen, R.H.; Tsao, S.M.; Hsu, J. Fucoidan induces changes in the epithelial to mesenchymal transition and decreases metastasis by enhancing ubiquitin-dependent TGFbeta receptor degradation in breast cancer. Carcinogenesis 2013, 34, 874-884. [CrossRef] [PubMed]

18. Hsu, H.Y.; Lin, T.Y.; Wu, Y.C.; Tsao, S.M.; Hwang, P.A.; Shih, Y.W.; Hsu, J. Fucoidan inhibition of lung cancer in vivo and in vitro: Role of the Smurf2-dependent ubiquitin proteasome pathway in TGF $\beta$ receptor degradation. Oncotarget 2014, 5, 7870-7885. [CrossRef] [PubMed]

19. Yan, M.D.; Yao, C.J.; Chow, J.M.; Chang, C.L.; Hwang, P.A.; Chuang, S.E.; Whang-Peng, J.; Lai, G.M. Fucoidan Elevates MicroRNA-29b to Regulate DNMT3B-MTSS1 Axis and Inhibit EMT in Human Hepatocellular Carcinoma Cells. Mar. Drugs 2015, 13, 6099-6116. [CrossRef] [PubMed]

20. Takahashi, H.; Kawaguchi, M.; Kitamura, K.; Narumiya, S.; Kawamura, M.; Tengan, I.; Nishimoto, S.; Hanamure, Y.; Majima, Y.; Tsubura, S.; et al. An Exploratory Study on the Anti-inflammatory Effects of Fucoidan in Relation to Quality of Life in Advanced Cancer Patients. Integr. Cancer Ther. 2017. [CrossRef]

21. Taiwan Cancer Registry. Available online: http://tcr.cph.ntu.edu.tw/main.php?Page=A5B2 (accessed on 7 December 2016).

22. Hwang, P.A.; Phan, N.N.; Lu, W.J.; Ngoc Hieu, B.T.; Lin, Y.C. Low-molecular-weight fucoidan and high-stability fucoxanthin from brown seaweed exert prebiotics and anti-inflammatory activities in Caco-2 cells. Food Nutr. Res. 2016, 60, 32033. [CrossRef] [PubMed]

23. Haugan, K.; Karunakaran, P.; Blatny, J.M.; Valla, S. The phenotypes of temperature-sensitive mini-RK2 replicons carrying mutations in the replication control gene $\operatorname{trf} \mathrm{A}$ are suppressed nonspecifically by intragenic cop mutations. J. Bacteriol. 1992, 174, 7026-7032. [CrossRef] [PubMed]

24. Eisenhauer, E.A.; Therasse, P.; Bogaerts, J.; Schwartz, L.H.; Sargent, D.; Ford, R.; Dancey, J.; Arbuck, S.; Gwyther, S.; Mooney, M.; et al. New response evaluation criteria in solid tumours: Revised RECIST guideline (version 1.1). Eur. J. Cancer 2009, 45, 228-247. [CrossRef] [PubMed]

25. National Cancer Institute. Available online: https://evs.nci.nih.gov/ftp1/CTCAE/About.html (accessed on 7 December 2016).

26. Ferlay, J.; Shin, H.R.; Bray, F.; Forman, D.; Mathers, C.; Parkin, D.M. Estimates of worldwide burden of cancer in 2008: GLOBOCAN 2008. Int. J. Cancer 2010, 127, 2893-2917. [CrossRef] [PubMed]

27. Zhao, B.; Wang, L.; Qiu, H.; Zhang, M.; Sun, L.; Peng, P.; Yu, Q.; Yuan, X. Mechanisms of resistance to anti-EGFR therapy in colorectal cancer. Oncotarget 2017, 8, 3980-4000. [CrossRef] [PubMed] 
28. Troiani, T.; Napolitano, S.; Della Corte, C.M.; Martini, G.; Martinelli, E.; Morgillo, F.; Ciardiello, F. Therapeutic value of EGFR inhibition in CRC and NSCLC: 15 years of clinical evidence. ESMO Open 2016, 1, 1-14. [CrossRef] [PubMed]

29. Saltz, L.B.; Meropol, N.J.; Loehrer, P.J., Sr.; Needle, M.N.; Kopit, J.; Mayer, R. Phase II trial of cetuximab in patients with refractory colorectal cancer that expresses the epidermal growth factor receptor. J Clin. Oncol. 2004, 22, 1201-1208. [CrossRef] [PubMed]

30. Van Cutsem, E.; Peeters, M.; Siena, S.; Humblet, Y.; Hendlisz, A.; Neyns, B.; Canon, J.L.; Van Laethem, J.L.; Maurel, J.; Richardson, G.; et al. Open-label phase III trial of panitumumab plus best supportive care compared with best supportive care alone in patients with chemotherapy-refractory metastatic colorectal cancer. J. Clin. Oncol. 2007, 25, 1658-1664. [CrossRef] [PubMed]

31. De Roock, W.; Claes, B.; Bernasconi, D.; De Schutter, J.; Biesmans, B.; Fountzilas, G.; Kalogeras, K.T.; Kotoula, V.; Papamichael, D.; Laurent-Puig, P.; et al. Effects of KRAS, BRAF, NRAS, and PIK3CA mutations on the efficacy of cetuximab plus chemotherapy in chemotherapy-refractory metastatic colorectal cancer: A retrospective consortium analysis. Lancet Oncol. 2010, 11, 753-762. [CrossRef]

32. Hsu, H.C.; Thiam, T.K.; Lu, Y.J.; Yeh, C.Y.; Tsai, W.S.; You, J.F.; Hung, H.Y.; Tsai, C.N.; Hsu, A.; Chen, H.C.; et al. Mutations of KRAS/NRAS/BRAF predict cetuximab resistance in metastatic colorectal cancer patients. Oncotarget 2016, 7, 22257-22270. [PubMed]

33. Bos, J.L. Ras oncogenes in human cancer: A review. Cancer Res. 1989, 49, 4682-4689. [PubMed]

34. Fernandez-Medarde, A.; Santos, E. Ras in cancer and developmental diseases. Genes Cancer 2011, 2, 344-358. [CrossRef] [PubMed]

35. Somasundaram, S.N.; Shanmugam, S.; Subramanian, B.; Jaganathan, R. Cytotoxic effect of fucoidan extracted from Sargassum cinereum on colon cancer cell line HCT-15. Int. J. Biol. Macromol. 2016, 91, 1215-1223. [CrossRef] [PubMed]

36. Han, Y.S.; Lee, J.H.; Lee, S.H. Fucoidan inhibits the migration and proliferation of HT-29 human colon cancer cells via the phosphoinositide-3 kinase/Akt/mechanistic target of rapamycin pathways. Mol. Med. Rep. 2015, 12, 3446-3452. [CrossRef] [PubMed]

37. Huang, T.H.; Chiu, Y.H.; Chan, Y.L.; Chiu, Y.H.; Wang, H.; Huang, K.C.; Li, T.L.; Hsu, K.H.; Wu, C.J. Prophylactic administration of fucoidan represses cancer metastasis by inhibiting vascular endothelial growth factor (VEGF) and matrix metalloproteinases (MMPs) in Lewis tumor-bearing mice. Mar. Drugs 2015, 13, 1882-1900. [CrossRef] [PubMed]

38. Li, J.; Chen, K.; Li, S.; Liu, T.; Wang, F.; Xia, Y.; Lu, J.; Zhou, Y.; Guo, C. Pretreatment with Fucoidan from Fucus vesiculosus Protected against ConA-Induced Acute Liver Injury by Inhibiting Both Intrinsic and Extrinsic Apoptosis. PLoS ONE 2016, 11, e0152570. [CrossRef] [PubMed]

39. Li, J.; Chen, K.; Li, S.; Feng, J.; Liu, T.; Wang, F.; Zhang, R.; Xu, S.; Zhou, Y.; Zhou, S.; et al. Protective effect of fucoidan from Fucus vesiculosus on liver fibrosis via the TGF-beta1/Smad pathway-mediated inhibition of extracellular matrix and autophagy. Drug Des. Dev. Ther. 2016, 10, 619-630.

40. Jia, Y.; Sun, Y.; Weng, L.; Li, Y.; Zhang, Q.; Zhou, H.; Yang, B. Low molecular weight fucoidan protects renal tubular cells from injury induced by albumin overload. Sci. Rep. 2016, 6, 31759. [CrossRef] [PubMed]

41. Chen, J.; Cui, W.; Zhang, Q.; Jia, Y.; Sun, Y.; Weng, L.; Luo, D.; Zhou, H.; Yang, B. Low molecular weight fucoidan ameliorates diabetic nephropathy via inhibiting epithelial-mesenchymal transition and fibrotic processes. Am. J. Transl. Res. 2015, 7, 1553-1563. [PubMed]

42. Zuo, T.; Li, X.; Chang, Y.; Duan, G.; Yu, L.; Zheng, R.; Xue, C.; Tang, Q. Dietary fucoidan of Acaudina molpadioides and its enzymatically degraded fragments could prevent intestinal mucositis induced by chemotherapy in mice. Food Funct. 2015, 6, 415-422. [CrossRef] [PubMed]

43. Hu, C.; Zhang, G.; Zhao, Y.T. Fucoidan attenuates the existing allodynia and hyperalgesia in a rat model of neuropathic pain. Neurosci. Lett. 2014, 571, 66-71. [CrossRef] [PubMed]

(C) 2017 by the authors. Licensee MDPI, Basel, Switzerland. This article is an open access article distributed under the terms and conditions of the Creative Commons Attribution (CC BY) license (http:/ / creativecommons.org/licenses/by/4.0/). 